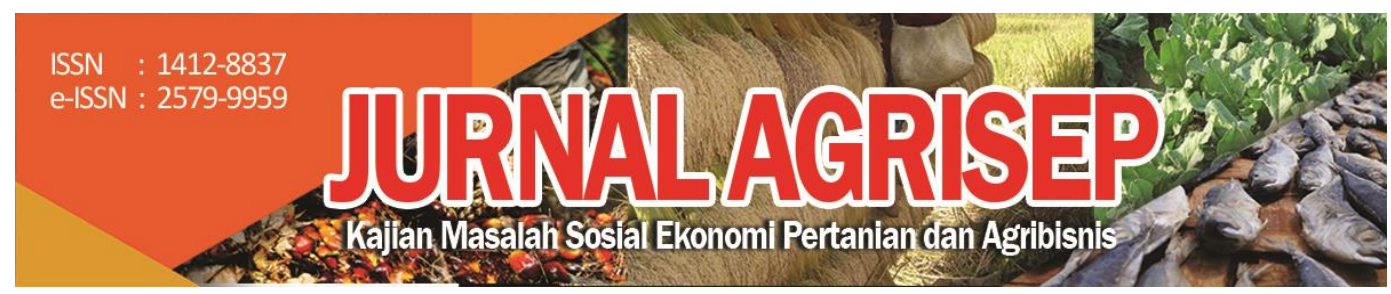

DOI: $10.31186 /$ jagrisep.19.1.1-14

\title{
ADOPSI STANDAR INDIKASI GEOGRAFIS OLEH PETANI KOPI ROBUSTA DI KABUPATEN TEMANGGUNG
}

\author{
Adoption Of Geographical Indication Standards \\ By Robusta Coffee Farmers In Temanggung District
}

\author{
Nuning Setyowati Sumarjo1), Hanifah Ihsaniyati Ihsaniyati²), Pardono \\ Pardono Pardono 3 ) \\ 1),2),3) Fakultas pertanian Universitas Sebelas Maret \\ Email: nuning_s@staff.uns.ac.id
}

\begin{abstract}
Coffee is a superior commodity that has a big role in the Indonesian economy. Temanggung Regency is one of the regions in Central Java that has a high coffee production and broad market share, especially for Robusta coffee. The quality of coffee is determined by geographical factors, the process of cultivation and post harvest processing. Geographical indications are expected to create the unique character of Temanggung robusta coffee. Geographical Indication Standards for Temanggung Robusta Coffee have been prepared. This study aims to identify the level of adoption of Temanggung Robusta coffee IG standards, identify farmers' perceptions of the benefits and constraints in the adoption of Temanggung Robusta coffee IG standards. The research method used descriptive method. Data was collected using a survey with a number of respondents 220 farmers spread across 11 subdistricts Robusta coffee centers. The data analysis method used the scoring method. The results showed that overall the level of adoption of IG standards by coffee farmers was still at the interested stage, although for some standards it had already reached the evaluation, tried and even adoption stages. Farmers have a very high perception of the benefits of adopting IG standards. But, on the other hand farmers still feel constrained in adopting IG standards because farmers are still constrained by high costs, greater labor and time and no price guarantees for coffee produced according to IG standards Collaboration with the government, the private sector, universities and MPIG is needed to provide education, facilitation and assistance in the process of adopting IG standards in order to produce good quality, unique coffee and high competitiveness
\end{abstract}


Keywords: robusta coffee, temanggung, adoption, benefits, constraints

\begin{abstract}
ABSTRAK
Kopi adalah salah satu komoditas istimewa yang memiliki peran besar perekonomian Indonesia. Kabupaten Temanggung merupakan salah satu daerah di Jawa Tengah yang memiliki produksi kopi yang tinggi dan pangsa pasar yang luas, khususnya untuk kopi robusta. Mutu kopi ditentukan oleh faktor geografis, proses budidaya dan pengolahan pasca panen. Indikasi geografis diharapkan mampu menciptakan keunikan karakter kopi robusta Temanggung. Standar Indikasi Geografis Kopi Robusta Temanggung telah disusun. Penelitian ini bertujuan untuk mengidentifikasi tingkat adopsi standar IG kopi robusta Temanggung, mengidentifikasi persepsi petani terhadap manfaat dan kendala dalam adopsi standar IG kopi robusta Temanggung. Metode penelitian yang digunakan adalah metode deskrriptif. Pengambilan data dilakukan menggunakan survei dengan jumlah responden 220 petani yang tersebar di 11 kecamatan di kabupaten Temanggung yang merupakan kecamatan penghasil kopi robusta. Metode analisis data menggunakan metode skoring. Hasil penelitian menunjukkan bahwa secara keseluruhan tingkat adopsi standar IG oleh petani kopi masih pada tahap tertarik, walaupun untuk beberapa standar sudah sampai pada tahap evaluasi, mencoba dan bahkan adopsi. Petani memiliki persepsi sangat tinggi terhadap manfaat adopsi standar IG. Namun, disisi lain petani merasa terkendala dalam adopsi standar IG. Diperlukan kerja bersama pemerintah, sektor swasta, universitas dan MPIG untuk memberikan edukasi, fasilitasi dan pendampingan dalam proses adopsi standar IG dalam rangka menghasilkan kopi dengan kualitas baik, memiliki keunikan dan daya saing tinggi.
\end{abstract}

Kata kunci: kopi robusta, temanggung, adopsi, manfaat, kendala

\title{
PENDAHULUAN
}

Komoditas kopi memiliki kontribusi besar bagi perekonomian di Indonesia. Kopi menjadi komoditi unggulan untuk pasar luar negeri, menjadi sumber pendapatan bagi petani dan menjadi bahan baku bagi industri kopi di Indonesia. Salah satu daerah penghasil kopi di Indonesia adalah Kabupaten Temanggung. Pertanaman kopi tercatat lebih dari 11.000 ha, pada tahun 2015. Dari luas tersebut, 8.158,55 ha diantaranya merupakan areal pertanaman kopi Robusta dengn produksi sekitar $10.254,32$ ton, atau rata-rata produktivitas di atas 1,2 ton / ha. Pengembangan agribisnis komoditas kopi robusta di Kabupaten Temanggung masih cukup terbuka, baik melalui program perluasan, intensifikasi untuk peningkatan produtivitas, maupun perbaikan mutu dan pengembangan industri hilir. Kopi robusta yang dihasilkan dari daerah ini, diharapkan mempunyai potensi menjadi produk kopi spesial( specialty coffee) karena memiliki karakter cita rasa yang khas (MPIG, 2015).

2 |Nuning Setyowati Sumarjo; Hanifah Ihsaniyati Ihsaniyati; Pardono; Adop.. 
Peran perlindungan Indikasi Geografis (IG) sangat penting. Masyarakat produsen lokal membutuhkan perlindungan hukum terhadap nama asal produk agar tidak dipergunakan oleh pihak lain untukmelakukan persaingan tidak sehat. Semakin kuatnya persaingan pada era pasar global di beberapa dekade belakangan ini, semakin pentingnya IG yang dapat melindungi suatu ciri khas suatu produk (Ellyanti et al, 2012). Sejak tahun 2016, Kementerian Hukum dan HAM telah menyetujui ajuan Perlindungan Indikasi Geografis Kopi Robusta Temanggung yang merupakan standar dalam budidaya dan pasca panen kopi. Kopi yang diproduksi dan diolah sesuai standar IG akan memiliki nilai tambah yang lebih baik, daya saing yang lebih tinggi, dan harga yang lebih baik. Brand kopi robusta untuk kopi berbasis IG disebut Kopi Robusta Temanggung. Standar yang ditetapkan dalam IG Kopi Robusta Temanggung meliputi standar sifat fisik, mutu citarasa, metode produksi (on farm), panen dan pasca panen, dan metode pengolahan.

Kondisi saat ini, penerapan standar IG oleh petani kopi robusta di Kabupaten Temanggung masih sangat terbatas. Beragam persepsi dari petani mengenai standar IG menyebabkan keraguan dan kekhawatiran bagi petani untuk mengadopsinya. kekhawatiran akan jaminan harga yang didapat dengan menerapkan standar IG, perubahan budaya atau cara budidaya yang selama ini dilakukan sulit untuk dilakukan dan keterbatasan informasi dan sharing pengalaman mengenai manfaat penerapan standar IG menyebabkan motivasi untuk menerapkan standar IG masih rendah.

Penelitian ini bertujuan untuk mengidentifikasi tingkat adopsi standar IG kopi robusta Temanggung oleh petani, menganalisis persepsi petani kopi terhadap manfaat dan kendala dalam penerapan standar IG. Pemetaan kondisi ini menjadi penting untuk dilakukan karena merupakan dasar bagi perumusan strategi atau solusi dalam mempercepat adopsi standar IG oleh petani kopi robusta di Kabupaten Temanggung.

\section{METODE PENELITIAN}

Penelitian ini dilihat dari jenis masalah serta tujuannya merupakan penelitian deskriptif dengan teknik survei. Teknik survei yaitu penelitian yang mengambil sampel dari suatu populasi dan menggunakan kuisioner sebagai alat bantu pengumpulan data yang pokok. Teknik survei digunakan untuk mendapatkan data dari tempat tertentu yang alamiah (bukan buatan), tetapi peneliti melakukan perlakuan dalam pengumpulan data, misalnya dengan mengedarkan kuesioner, tes, dan wawancara yang terstruktur. Menggunakan teknik survei, peneliti dapat memperoleh fakta-fakta dari fenomena yang timbul dan mencari keterangan secara faktual. Dalam teknik survei, instrumen penelitian menggunakan pertanyaan atau pernyataan terstruktur dan sistematis yang sama kepada kelompok tertentu sesuai dengan sasaran 
penelitian yang kemudian seluruh jawaban yang diperoleh dicatat, diolah dan dianalisis (Sugiyono, 2014).

\section{Teknik Pengumpulan Data}

Penelitian ini menggunakan teknik sampling dalam memilih lokasi penelitian dan sampel. Peneliti mempunyai pertimbangan-pertimbangan tertentu di dalam pengambilan sampelnya atau penentuan sampel untuk tujuan tertentu (Riduwan dan Akdon, 2005). Penelitian ini dilakukan di 11 kecamatan di kabupaten Temanggung yang merupakan kecamatan penghasil kopi robusta antara lain kecamatan Bejen, Gemawang, Candiroto, Kandangan, Pringsurat, Wonoboyo, Tretep, Kaloran, Kranggan, Kedu dan Jumo. Jumlah responden yang diambil sebanyak 220 petani dengan perbandingan kecamatan: responden adalah 1:20 petani kopi. Teknik penentuan responden dilakukan secara purposive (sengaja). Petani kopi yang menjadi responden adalah petani kopi yang minimal berpengalaman membudidayakan kopi selama 5 tahun.

\section{Analisis Data}

Pemetaan tingkat adopsi IG oleh petani menggunakan analisis deskriptif dengan memaparkan hasil analisis data mengenai tingkat penerapan IG dalam budidaya dan pasca panen, persepsi petani terhadap manfaat dan kendala penerapan IG serta informasi pendukung lainnya. Untuk pengumpulan data menggunakan skala likert 1-5 (1: sangat setuju sampai 5: sangat tidak setuju) dan analisis data menggunakan metode skoring. Penggunaan skala Likert menurut Sugiyono (2014) adalah "skala Likert digunakan untuk mengukur sikap, pendapat dan persepsi seseorang atau sekelompok orang tentang fenomena sosial". Analisis data menggunakan metode skoring dengan membagi data menjadi 5 klasifikasi untuk tingkat adopsi (Awareness, Interest, Evaluation, Trial dan Adoption) dan 5 klasifikasi untuk persepsi terhadap manfaat dan kendala adopsi IG (sangat rendah, rendah, cukup, tinggi dan sangat tinggi).

\section{HASIL DAN PEMBAHASAN}

Adopsi IG oleh petani kopi ditentukan bagaimana persepsi petani terhadap manfaat dan kendala dalam menerapkan IG. Penelitian ini bertujuan untuk memperoleh gambaran mengenai tingkat adopsi IG oleh petani dan persepsi petani terhadap manfaat dan kendala dalam mengadopsi IG. Adapun hasil analisis data adalah sebagai berikut:

4 |Nuning Setyowati Sumarjo; Hanifah Ihsaniyati Ihsaniyati; Pardono; Adop.. 
Tabel 1. Tingkat Adopsi Standar IG Kopi Robusta

\begin{tabular}{|c|c|c|}
\hline SOP & Rerata & Interpretasi \\
\hline $\begin{array}{l}\text { Penanaman memperhatikan aturan jarak } \\
\text { tanam }\end{array}$ & 3,64 & Trial \\
\hline $\begin{array}{l}\text { Menyiapkan tanaman penaung yang } \\
\text { cocok sebelum bibit kopi robusta ditanam }\end{array}$ & 3,67 & Trial \\
\hline $\begin{array}{l}\text { Menggunakan bibit tanaman berkualitas } \\
\text { baik }\end{array}$ & 3,95 & Trial \\
\hline $\begin{array}{l}\text { Pengendalian gulma dilakukan } 2 \text { kali } \\
\text { dalam setahun }\end{array}$ & 4,08 & Adoption \\
\hline $\begin{array}{l}\text { Panen dilakukan secara manual dan } \\
\text { selektif menggunakan tangan }\end{array}$ & 4,23 & Adoptian \\
\hline $\begin{array}{l}\text { Kopi robusta harus dipanen saat } \\
\text { gelondong telah berwarna merah (petik } \\
\text { merah) dengan prosentase } 95 \% \text { dan } 100 \% \\
\text { untuk kopi madu }\end{array}$ & 3,27 & Trial \\
\hline $\begin{array}{l}\text { Memisahkan buah yang sudah rontok dan } \\
\text { jatuh ke tanah sebelum panen dengan } \\
\text { buah merah segar yang dipetik }\end{array}$ & 2,97 & Evaluation \\
\hline $\begin{array}{l}\text { Buah kopi hasil panen diolah dalam } \\
\text { waktu kurang dari } 24 \text { jam }\end{array}$ & 2,33 & Evaluation \\
\hline $\begin{array}{l}\text { Pengolahan buah kopi yang dipanen } \\
\text { dilakukan di UPH (Unit Pengolahan } \\
\text { Hasil) }\end{array}$ & 1,81 & Interest \\
\hline $\begin{array}{l}\text { Pengolahan buah kopi (olah basah, olah } \\
\text { kering, kopi madu) diawali dengan sortasi } \\
\text { kematangan buah, buah yang belum } \\
\text { merah dipisahkan }\end{array}$ & 2,45 & Evaluation \\
\hline $\begin{array}{l}\text { Sortasi dilakukan untuk memperoleh } 95 \% \\
\text { buah kopi merah segar dan sehat (BMSS) } \\
\text { dan maksimal } 5 \% \text { buah kopi berwarna } \\
\text { kuning (olah basah, olah kering) }\end{array}$ & 2,58 & Evaluation \\
\hline
\end{tabular}

Sumber : Analisis Data Primer, 2019 
Tabel 2. Tingkat Adopsi Standar IG Kopi Robusta Lanjutan

\begin{tabular}{|c|c|c|}
\hline SOP & Rerata & Interpretasi \\
\hline Sortasi dilakukan untuk memperoleh & & \\
\hline $\begin{array}{l}100 \% \text { buah kopi merah segar dan sehat } \\
\text { untuk kopi madu }\end{array}$ & 2,31 & Evaluation \\
\hline $\begin{array}{l}\text { Buah kopi berwarna hijau atau hitam } \\
\text { tidak boleh digunakan }\end{array}$ & 2,59 & Evaluation \\
\hline $\begin{array}{l}\text { Buah kopi yang mengambang dipisahkan } \\
\text { dari buah kopi yang tenggelam }\end{array}$ & 2,25 & Evaluation \\
\hline $\begin{array}{l}\text { Buah kopi yang mengambang tidak boleh } \\
\text { digunakan untuk menghasilkan Kopi } \\
\text { Robusta }\end{array}$ & 2,22 & Evaluation \\
\hline $\begin{array}{l}\text { Buah kopi yang tenggelam dikupas kulit } \\
\text { nya dengan mesin kupas kulit (pulper) } \\
\text { yang menggunakan air (olah basah) }\end{array}$ & 1,95 & Interest \\
\hline $\begin{array}{l}\text { Buah kopi yang telah di pulper selanjutnya } \\
\text { dirambang untuk memisahkan biji kopi } \\
\text { HS basah yang bernas dengan yang tidak } \\
\text { sempurna }\end{array}$ & 1,98 & Interest \\
\hline $\begin{array}{l}\text { Biji kopi HS basah yang tenggelam } \\
\text { disimpan dalam bak fermentasi selama } 12 \\
\text { - } 36 \text { jam }\end{array}$ & 1,92 & Interest \\
\hline $\begin{array}{l}\text { Biji kopi HS yang telah difermentasi harus } \\
\text { dicuci dan ditiriskan (olah basah) }\end{array}$ & 1,94 & Interest \\
\hline
\end{tabular}

Sumber : Analisis Data Primer, 2019

Tingkat adopsi standar IG oleh petani kopi dapat dikatakan rata rata masih rendah. Secara rata rata tingkat adopsi standar IG masih dalam tahap "tertarik", namun pada beberapa kriteria petani sudah sampai pada tahap "evaluasi", "mencoba" dan "mengadopsi".

Standar IG yang di adopsi petani masih pada presentase 9,5\% yaitu pada kriteria 1) Penanganan gulma yang dilakukan minimal setahun 2 kali dan 2) Pemetikan buah secara selektif dan manual. Petani lebih mudah melakukan kedua standar tersebut dikarenakan standar tersebut selalu dilakukan setiap tahunnya dan berhubungan dengan budidaya di lahan. Penggunaan standar tersebut juga merupakan standar minimal agar tanaman kopi tumbuh sehat. Dalam pemanenan petani melakukannnya dengan cara manual dan selektif. Namun selektif 6 INuning Setyowati Sumarjo; Hanifah Ihsaniyati Ihsaniyati; Pardono; Adop.. 
disini hanya pada tahap pemisahan biji busuk saja, rata rata belum sampai pada panen selektif petik merah dikarenakan beberapa faktor seperti keamanan dan desakan kebutuhan ekonomi sehari-hari.

Standar yang mulai di coba petani pada presentase $19 \%$ meliputi, 1) Penanaman yang memperhatikan aturan jarak tanam, 2) Penyiapan tanaman penaung yang cocok sebelum bibit kopi robusta ditanam, 3) Penggunaan bibit tanaman berkualitas baik dan unggul, 4) Pemanenan gelondong telah berwarna merah (petik merah) dengan prosentase $95 \%$ dan $100 \%$ untuk kopi madu. Sebagian petani sudah mencoba menerapkan standar IG, penggunan jarak tanam yang sesuai adalah 2,5 $\mathrm{m} \times 2,5 \mathrm{~m}$ dan $3 \mathrm{~m} \times 3 \mathrm{~m}$. Sebagian petani juga sudah menggunakan tanaman penaung yang cocok dengan tanaman kopi seperti tanaman sengon, risidi dan lamtoro. Akan tetapi sebagian petani masih menerapkan jarak penaung yang kurang beraturan sehingga berpengaruh terhadap produksi kopi. Penggunaan bibit unggul sudah dilakukan petani. Petani lebih senang mencoba bibit unggul dan tahan terhadap penyakit. Bibit kopi yang sering digunakan petani adalah bibit kopi lokal untuk batang bawah dan kombinasi Tugusari atau Sariayu untuk batang produksi atau batang atas. Petani kopi robusta Temanggung sebagian juga sudah melakukan petik merah, petani yang melakukan petik merah biasanya adalah petani yang memiliki banyak jejaring pemasaran dan memiliki lahan yang luas. Selain itu, pembeli mampu menampung hasil panen petik merah dengan selisih harga yang lebih tinggi dari petik asalan. Namun, sebagian besar petani kopi masih menerapkan petik asalan yaitu memetik biji kopi yang sudah merah dan hijau sekaligus. Hal ini sejalan dengan temuan Yulistriani et al (2019) bahwa pengetahuan petani mengenai cara panen yang baik masih terbatas.

Standar yang masih pada tahap "evaluasi" oleh petani pada presentase $48 \%$ meliputi, 1) Pemisahan buah yang sudah rontok dan jatuh ke tanah sebelum panen dengan buah merah segar yang dipetik, 2) Pengolahan buah kopi hasil panen diolah dalam waktu kurang dari 24 jam, 3) Pengolahan buah kopi (olah basah, olah kering, kopi madu) diawali dengan sortasi kematangan buah, buah yang belum merah dipisahkan, 4) Sortasi yang dilakukan untuk memperoleh 95\% buah kopi merah segar dan sehat dan maksimal $5 \%$ buah kopi berwarna kuning 
(olah basah, olah kering), 5) Sortasi yang dilakukan untuk memperoleh 100\% buah kopi merah segar dan sehat untuk kopi madu, 6) Penggunaan buah kopi berwarna hijau atau hitam tidak diperkenankan, 7) Pengolahan hasil sortasi yang berupa buah yang belum merah dibolehkan tetapi tidak dijual dengan nama Kopi Robusta Temanggung, 8) Melakukan perambangan BMSS menggunakan air bersih, pada saat perambangan buah kopi yang mengambang dipisahkan dari buah kopi yang tenggelam, 9) buah kopi yang mengambang tidak boleh digunakan untuk menghasilkan Kopi Robusta Temanggung.

Sebagian besar petani masih melakukan evaluasi terhadap standar IG untuk mengetahui apakah penerapan standar tersebut menguntungkan atau tidak. Rata rata petani belum bisa menerapkan standar ini dikarenakan petani kopi dikabupaten Temanggung masih pada tahap petani pelaku budidaya. Belum banyak petani di Kabupaten Temanggung yang terjun dalam pengolahan atau pengrajin kopi. Data dari dinas Diskoperindag dan UMKM kabupaten Temanggung menjelaskan bahwa sementara ini baru terdapat 65 pengolah kopi bubuk. Jumlah tersebut tentunya kecil sekali mengingat perkopian Temanggung sangat luas dan produksinya sangat tinggi. Petani enggan mengolah kopinya dikarenakan jumlah produksi kopi relatif sedikit dan kemampuan SDM petani masih rendah untuk melakukan proses pasca panen kopi. Selain itu petani kopi robusta juga terkendala permodalan dan kebutuhan sehingga petani berfikir dua kali untuk melakukan pengolahan. Petani lebih memilih menjual langsung hasil panen kopi dan itupun yang dijual kebanyakan petik asalan bukan petik merah 95\%. Pangsa pasar kopi olahan dikabupaten Temanggung juga masih sedikit, terbatasnya akses pemasaran kopi olahan juga membuat petani kopi di Kabupaten Temanggung enggan mengolah kopinya.

Standar IG yang masih belum dilaksanakan petani namun petani mulai tertarik untuk menerapkan memiliki presentase $23 \%$ yaitu meliputi, 1) Pengolahan buah kopi yang dipanen dilakukan di UPH (Unit Pengolahan Hasil), 2) Biji kopi hasil sortasi yang telah difermentasi harus dicuci dan ditiriskan (olah basah), 3) Biji kopi HS basah yang tenggelam disimpan dalam bak fermentasi selama 12 - 36 jam (olah basah), 4) Buah kopi yang telah di pulper selanjutnya harus dirambang kembali untuk memisahkkan biji kopi HS basah yang bernas dengan 8 |Nuning Setyowati Sumarjo; Hanifah Ihsaniyati Ihsaniyati; Pardono; Adop.. 
yang tidak sempurna (olah basah), 5) Buah kopi yang tenggelam dikupas kulit nya dengan mesin kupas kulit yang menggunakan air (olah basah). Beberapa standar IG tersebut belum dilaksanakan petani dikarenakan beberapa alasan antara lain; Petani jarang melakukan pengolahan biji kopi di UPH karena ketersediaan UPH masih sedikit. Petani banyak yang belum melakukan olah basah pada pascapanennya karena banyak petani yang langsung menjual gelondong karena keterbatasan alat pasca panen seperti pulper dan huller. Selain itu, pengetahuan petani tentang pengolahan pasca panen masih terbatas sehingga petani belum bisa untuk mengolah sesuai standar pasar. Petani tidak melakukan sortasi basah sehingga petani hanya mensortasi biji baik dan biji busuk saja, belum ada sortasi dengan perambangan. Penggunaan pulper juga masih jarang di petani, kebanyakan petani menggunakan olah natural, prosedurnya meliputi kulit kopi di pecah dengan pemecah kulit setelah itu kopi dikeringkan dan di selep menggunakan penyelep kopi.

Dapat dilihat dari tabel 3. diketahui bahwa petani kopi memiliki persepsi yang sangat tinggi terhadap manfaat dari standar IG kopi robusta. Hal ini ditunjukkan dengan skor rata-rata 4.32. Petani kopi sangat memahami bahwa menerapkan standar IG kopi robusta dapat meningkatkan mutu kopi yang dihasilkan. Standar IG kopi robusta berisi standar-standar yang harus dipenuhi baik dalam budidaya maupun pasca panen kopi. Petani kopi juga sangat menyadari bahwa dengan menerapkan standar IG kopi robusta maka petani akan mendapatkan harga yang lebih baik. Hal ini karena kopi dengan kualitas baik akan dihargai lebih tinggi dipasaran. Petani kopi memiliki persepsi yang sangat tinggi bahwa dengan menerapkan standar IG kopi robusta akan mampu meningkatkan produktifitas usaha tani kopi. Proses budidaya kopi yang memperhatikan standar-standar budidaya yang benar akan mendorong produktifitas yang tinggi. Selain itu, petani juga sangat menyadari bahwa penerapan standar IG kopi robusta juga akan meningkatkan daya saing kopi robusta di tengah persaingan industri kopi. Daya saing kopi sangat ditentukan oleh mutu kopi. Mutu kopi ditentukan oleh proses budidaya dan pasca panen yang tepat sesuai standar. Penerapan standar IG kopi robusta yang benar oleh petani kopi 
akan mendorong dhasilkannya biji kopi yang berkualitas dan mampu menampilkan keunikan kopi robusta Temanggung.

Tabel 3. Persepsi Petani Terhadap Manfaat Standar Indikasi Geografis Kopi Robusta

\begin{tabular}{|c|c|c|}
\hline Persepsi Manfaat & Skor & Keterangan \\
\hline $\begin{array}{l}\text { Menerapkan Standar IG Kopi Robusta } \\
\text { dapat meningkatkan mutu kopi yang saya } \\
\text { hasilkan }\end{array}$ & 4,36 & Sangat Tinggi \\
\hline $\begin{array}{l}\text { Menerapkan Standar IG Kopi Robusta } \\
\text { dapat menghasilkan kopi dengan harga } \\
\text { yang lebih baik di pasar }\end{array}$ & 4,32 & Sangat Tinggi \\
\hline $\begin{array}{l}\text { Menerapkan Standar IG Kopi Robusta } \\
\text { mampu meningkatkan produktifitas } \\
\text { usaha tani kopi yang saya jalankan }\end{array}$ & 4,28 & Sangat Tinggi \\
\hline $\begin{array}{l}\text { Menerapkan Standar IG Kopi Robusta } \\
\text { mampu meningkatkan daya saing Kopi } \\
\text { Robusta Temanggung }\end{array}$ & 4,42 & Sangat Tinggi \\
\hline $\begin{array}{l}\text { Menerapkan Standar IG Kopi Robusta } \\
\text { memberikan manfaat secara ekonomi bagi } \\
\text { saya }\end{array}$ & 4,25 & Sangat Tinggi \\
\hline $\begin{array}{l}\text { Menerapkan Standar IG Kopi Robusta } \\
\text { dapat menarik minat buyer potensial }\end{array}$ & 4,32 & Sangat Tinggi \\
\hline Skor Rata-Rata & 4,32 & Sangat Tinggi \\
\hline
\end{tabular}

Sumber : Analisis Data Primer, 2019

Petani kopi juga memiliki persepsi yang sangat tinggi bahwa penerapan standar IG kopi robusta dapat meningkatkan ekonomi keluarga. Dengan menghasilkan kopi berkualitas baik, petani akan mendapatkan harga yang lebih tinggi dan diharapkan keuntungan yang didapat juga semakin tinggi. Persepsi yang sangat tinggi terkait manfaat penerapan standar IG kopi robusta adalah mampu menarik buyer potensial. Hal ini karena kopi yang berkualitas selalu diminati pasar. Buyer akan mempertimbangkan mutu ketika membeli kopi. Kopi yang berkualitas baik akan lebih mudah dalam bersaing mendapatkan buyer potensial. Persepsi manfaat terhadap suatu teknologi atau inovasi akan mendukung kesuksesan dari teknologi tersebut. Hal ini sejalan dengan hasil penelitian (Maredia dan Minde, 2002) bahwa ada hubungan antara keuntungan suatu teknologi pertanian dengan adopsinya oleh petani. 10 |Nuning Setyowati Sumarjo; Hanifah Ihsaniyati Ihsaniyati; Pardono; Adop.. 
Sebagai contoh, varietas kopi yang menguntungkan mendorong keberhasilan proses adopsi nya di Kenya.

Tabel 4. Persepsi Terhadap Kendala Penerapan Standar IG

\begin{tabular}{|c|c|c|}
\hline Persepsi Kendala & Skor & Keterangan \\
\hline $\begin{array}{l}\text { Penerapan Standar IG Kopi Robusta } \\
\text { memerlukan biaya yang besar }\end{array}$ & 3,32 & Tinggi \\
\hline $\begin{array}{l}\text { Penerapan Standar IG Kopi Robusta } \\
\text { memerlukan waktu dan tenaga lebih } \\
\text { banyak }\end{array}$ & 3,49 & Tinggi \\
\hline $\begin{array}{l}\text { Biaya yang saya keluarkan untuk } \\
\text { menerapkan Standar IG Kopi Robusta } \\
\text { tidak sebanding dengan manfaat yang } \\
\text { saya peroleh }\end{array}$ & 2,86 & Cukup \\
\hline $\begin{array}{l}\text { Sulit bagi saya untuk menemukan } \\
\text { pembeli/buyer yang bersedia membayar } \\
\text { lebih untuk kopi yang saya hasilkan } \\
\text { dengan penerapan Standar IG Kopi } \\
\text { Robusta }\end{array}$ & 3,38 & Tinggi \\
\hline $\begin{array}{l}\text { Sulit sekali bagi saya untuk menerapkan } \\
\text { Standar IG Kopi Robusta }\end{array}$ & 2,95 & Cukup \\
\hline $\begin{array}{l}\text { Saya lebih suka menerapkan cara } \\
\text { konvensional (seperti biasa) dalam } \\
\text { mengelola usaha tani kopi robusta }\end{array}$ & 2,97 & Cukup \\
\hline Skor Rata-Rata & 3,16 & Tinggi \\
\hline
\end{tabular}

Sumber : Analisis Data Primer, 2019

Berdasarkan tabel diketahui bahwa secara keseluruhan, petani kopi memiliki persepsi yang tinggi terhadap kendala dalam menerapkan standar indikasi geografis. Hal ini mengindikasikan bahwa meskipun petani menyadari besarnya manfaat adopsi standar IG dalam proses budidaya dan pasca panen, namun petani masih merasa terkendala untuk mengadopsi standar IG Kopi robusta. Kendala tinggi yang dihadapi petani antara lain terkait curahan tenaga, waktu dan biaya produksi yang lebih banyak jika menerapkan standar IG. Misalnya untuk proses pemeliharaan tanaman yang lebih intensif, panen petik merah yang artinya frekuensi panen harus lebih banyak, sortasi biji kopi basah yang harus lebih teliti dan standar lainnya. Banyak standar IG yang harus dipenuhi untuk menghasilkan kopi dengan kualitas baik dan 
mencirikan keunikan khas kopi robusta Temanggung. Kendala tinggi juga dirasakan bahwa petani sulit menemukan pembeli yang bersedia membayar lebih tinggi untuk green bean yang dihasilkan melalui penerapan standar IG baik pada proses budidaya dan pasca panen. Hal ini sejalan dengan hasil penelitian (Kumar et al, 2015) bahwa petani seringkali terkendala beberapa hal ketika mengadopsi inovasi baru antara lain biaya transportasi, pasar baru yang sulit dijangkau dan kesulitan secara teknis untuk menerapkannya.

Beberapa kendala yang cukup tinggi dirasakan petani antara lain bahwa petani merasa benefit yang didapat dengan menerapkan standar IG tidak sebanding dengan biaya yang dikeluarkan. Selain itu, petani juga merasa sulit untuk menerapkan standar IG dan lebih suka menerapkan cara konvensional dalam mengelola usaha tani kopi robusta. Hal ini mengindikasikan perlunya edukasi berupa pemahaman, pelatihan dan pendampingan dalam proses adopsi standar IG. Petani sulit beralih dari cara konvensional ke budidaya berbasis standar IG karena minimnya pengetahuan yang diperoleh dan terbatasnya sharing pengalaman sukses oleh petani yang telah menerapkan standar IG.

Peran penyuluh pertanian sangat penting dalam upaya meningkatkan motivasi petani untuk beralih dari sistem budidaya konvensional ke budidaya berbasis standar IG. Hal ini selaras dengan (Kiptot et al., 2011) bahwa melalui sistem penyuluhan yang terintegrasi dengan baik maka akan lebih efisien dan efektif dalam mendiseminasikan adopsi IG kepada petani kopi. Peran pemerintah dan organisasi ditingkat petani juga sangat vital dalam memberikan edukasi dan fasilitasi dalam adopsi standar IG. Hal ini sejalan dengan yang dinyatakan oleh (Mutoko et al., 2014 ) bahwa kondisi organisasi yang baik dan dukungan berbagai bentuk modal akan meningkatkan efisiensi adopsi dan difusi inovasi sehingga akan mampu mencapai target yang diharapkan. Selain itu, diperlukan kemitraan yang baik dengan pihak eksternal (perguruan tinggi, perbankan dan sektor swasta) untuk bersama-sama meningkatkan adopsi standar IG kopi robusta. Kemitraan dan kolaborasi yang efektif dapat menciptakan sinergi substansial untuk akselerasi adopsi suatu inovasi (Odongo, 2010).

12 |Nuning Setyowati Sumarjo; Hanifah Ihsaniyati Ihsaniyati; Pardono; Adop. . 


\section{SIMPULAN DAN SARAN}

\section{Simpulan}

Tingkat adopsi standar IG oleh petani kopi robusta di Kabupaten Temanggung masih pada tahap "interest". Petani memiliki persepsi sangat tinggi terhadap manfaat penerapan standar IG. Petani menyadari bahwa banyak manfaat yang diperoleh dengan menerapkan standar IG dalam budidaya dan pasca panen kopi robusta yang akan dapat meningkatkan mutu kopi robusta yang dihasilkan. Tetapi, petani memiliki persepsi tinggi terhadap kendala dalam penerapan standar IG kopi robusta terkait biaya, curahan tenaga dan waktu yang lebih besar untuk menerapkan standar IG namun belum ada jaminan harga yang tinggi untuk kopi robusta yang dihasilkan dengan menerapkan standar IG. Ada optimisme untuk terus mendorong adopsi standar IG oleh petani kopi karena pada dasarnya petani menyadari besarnya manfaat yang didapat ketika menerapkan standar IG. Namun, diperlukan upaya untuk mengatasi kendala yang dirasakan petani dalam mengadopsi standar IG antara lain melalui edukasi intensif, fasilitasi sumber daya sebagai stimuli dan kemitraan yang efektif dengan pihak eksternal misalnya buyer yang bersedia membeli kopi robusta yang diproduksi dengan standar IG. Dengan demikian diharapkan dapat memotivasi petani dan mendukung percepatan adopsi IG.

\section{Saran}

Diperlukan upaya bersama antara pemerintah dan pihak eksternal (sektor swasta, universitas, pihak swasta dan MPIG) untuk melakukan edukasi secara intensif, fasilitasi dan pendampingan secara kontinyu agar petani termotivasi untuk menerapkan standar IG sehingga proses adopsi standar IG oleh petani menjadi lebih mudah dan cepat. 


\section{DAFTAR PUSTAKA}

Ellyanti, Karim, A., dan Basri, H. 2012. Analisis Indikasi Geografis Kopi Arabika Gayo Ditinjaudari Rencana Tata Ruang Wilayah Kabupaten. Jurnal Agrista. 16(2). 46-61.

Kiptot, E., Lukuyu, B., Franzel, S., dan Place, F., 2011. The farmer trainers approach in technology dissemination in Kenya: farmer trainers and trainees perspectives, East Africa Dairy Development Project. Working Paper, Nairobi, Kenya.

Kumar, K.K.V., Praveen, dan Dharam, R.S. 2015. Economic Benefit of Organic Farming in India. Economic Affair. 60(3): 569-576.

Maredia, M. K., dan Minde, I. J. 2002. Technology profitability and agricultural transformation: Concepts, evidence, and policy implications. Perspectives on agricultural transformation: A view from Africa. 83116.

Masyarakat Perlindungan Indikasi Geografis (MPIG) Kopi Robusta Temanggung. 2015. Buku Persyaratan Permohonan Pendaftaran Perlindungan Indikasi Geografis Kopi Robusta Temanggung.

Mutoko, M.C., Hein, L., dan Shisanya, C.A. 2014. Farm diversity, resource use efficiency and sustainable land management in the western highlands of Kenya. Journal of Rural Studies. 36(1): 108-120.

Odongo, O.M. 2010. Need for effective collaboration and its challenges: Kenya Agricultural Research Institute's partnerships and collaborative efforts in agricultural research and development, KARI Mini- Scientific Conference, Nairobi, Kenya.

Riduwan dan Akdon. 2013. Teknik Penulisan Ilmiah, Teknik Penulisan Tesis, Karya Ilmiah. Bandung: Alfabeta.

Sugiyono. 2014. Metode Penelitian Pendidikan (Pendekatan Kuantitatif, Kualitatif, dan RED). Bandung : Alfabeta

Yulistriani, Yaherwandi dan Paloma, C. 2019. Roadmap pengembangan Kopi di Kabupaten Solok Selatan. AGRISEP.18(2): 279 - 288.

14 |Nuning Setyowati Sumarjo; Hanifah Ihsaniyati Ihsaniyati; Pardono; Adop.. 